Article

\title{
Managing Organisational Tensions in Cross-Sector Collaboration: The Case of Mediapolis
}

\author{
Sari Virta ${ }^{1}$ and Nando Malmelin ${ }^{2,3, *}$ \\ ${ }^{1}$ Jönköping International Business School, Jönköping University, Sweden \\ ${ }^{2}$ Faculty of Social Sciences, University of Helsinki, Finland \\ ${ }^{3}$ VTT Technical Research Center, Finland \\ * Corresponding author (nando.malmelin@vtt.fi)
}

Submitted: 22 April 2021 | Accepted: 2 August 2021 | Published: 20 January 2022

\begin{abstract}
Cross-sector collaboration combining public (non-commercial) and private (commercial) organisational orientations is considered an advantageous and dynamic strategic approach to shared value creation and co-creative innovation in disruptive operational environments of media industries. However, cross-sector collaboration features inherent complexities and organisational tensions due to the fundamental differences between the actors' strategies and operational models. This article explores organisational tensions and dualities in media work in the cross-sector collaboration of media clusters. The qualitative case study examines the development of the management approach and practical operations of the Finnish media cluster Mediapolis, which aims to produce value, especially through collaborative content and concept innovation. The case study builds on extensive empirical material collected since the Mediapolis project started in 2011 until 2018. The analysis focuses on the management of complexities and organisational tensions in implementing collaborative strategies at Mediapolis, as well as managing the shared operations and work of the cluster. The results reveal tensions between the core dualities in developing Mediapolis as a collaborative arrangement between the participating organisations in practice, despite shared strategic-level aspirations. The findings elaborate on the dynamics of different organisational orientations and business logics, discrepancies between visionary planning and practical actions, and opposing organisational interests and strategies as sources for organisational tensions in collaborative contexts. The article contributes to both the theoretical and practical knowledge on organisational tensions and their management in cross-sector collaboration in media cluster development and provides implications for managing respective complexities in media work.
\end{abstract}

\section{Keywords}

creative industries; cross-sector collaboration; media cluster; media industry; media work; Mediapolis; organisational tensions

\section{Issue}

This article is part of the issue "New Forms of Media Work and Its Organizational and Institutional Conditions" edited by Salla-Maaria Laaksonen (University of Helsinki) and Mikko Villi (University of Jyväskylä).

(C) 2022 by the author(s); licensee Cogitatio (Lisbon, Portugal). This article is licensed under a Creative Commons Attribution 4.0 International License (CC BY).

\section{Introduction}

Changes in the operational environment of creative industries have destabilised the equilibriums of legacy (i.e., traditional) media organisations during the last two decades (Küng, 2017b; Westlund, 2012). These changes include shifting to digital production technology and distribution, moving from mass production to coproduction, transforming broadcast media to convergent cross-media, consolidation and internationalisation of the media industry, and the creation of media clusters and organisational collaborations (e.g., Komorowski, 2017; Küng, 2017a; Picard \& Lowe, 2016; Villi \& Picard, 2019). As a result, the barriers to entry the industry have shifted and business models disrupted, originating complications for media companies' 
performance and profitability (Ess, 2014; Küng, 2017a, 2017b). Collaborative arrangements (for example, in the form of partnerships, value networks, and media clusters) are necessary to cope with the new reality (Lowe \& Stavitsky, 2016; Virta \& Lowe, 2017).

The fundamental changes in the media industry call for a shift in managing media organisations and their collaboration. Cross-sector collaboration combining public (non-commercial) and private (commercial) organisational orientations is considered an advantageous and dynamic strategic approach to shared value creation and co-creative innovation in disruptive operational environments. However, cross-sector collaboration features inherent complexities due to the fundamental differences between the strategies and operational models of the actors.

This study focuses on complexities of collaboration in media work (Deuze, 2007). The purpose of the article is to explore organisational tensions and dualities (e.g., Lewis et al., 2014; Sutherland \& Smith, 2011) of cross-sector collaboration in the work of media clusters, as well as their management. It utilises theorisations on collaborative dynamics and approaches, including hybrid organisations (e.g., Battilana \& Lee, 2014; Battilana et al., 2015; Jay, 2013). Hybrid organisations blur traditionally separate forms and logics between public (or non-commercial) and private (or commercial) organisations (Battilana et al., 2012). Combining these different aspects implies the necessity of collaboration, which is also considered to provide important means for managing the variety of tensions inherent to hybrid organisations (Battilana et al., 2015; Ramus et al., 2017). Previous research has emphasised dual relationships in collaborations (Sydow et al., 2013), but cross-sector collaboration in hybrid organisations among multiple partners is a more complex interplay of different dimensions.

The qualitative case study focuses on the development of management and operations at the media cluster Mediapolis (https://mediapolis.fi/en) in Finland. Mediapolis aims to produce value especially through collaborative content production and concept innovation in the context of digital creative industries. The case study builds on extensive empirical material (interviews, documentation, informal discussions, and feedback sessions) collected since the Mediapolis project started in 2011 until 2018. The abductive analysis (see, e.g., Jay, 2013) focuses on management of complexities and organisational tensions in implementing collaborative strategies at Mediapolis, as well as managing the shared work of the cluster.

The results reveal and elaborate on managerial tensions in developing Mediapolis as a collaborative arrangement between the participating organisations in practice, despite shared strategic-level aspirations for value creation. The article contributes to both theoretical and practical knowledge on organisational tensions and their management in cross-sector collaboration in media cluster development and media work.
More specifically, the article elaborates on the dynamics of different organisational orientations and business logics, discrepancies between ideal planning and practical actions as well as contending organisational interests, strategies and visions as sources for organisational tensions in collaborative contexts. The findings will be beneficial not only to media and creative industries, but also to other knowledge-intensive industries and organisations, where skilful management of creative organisations and their collaboration is crucial for competitive and collaborative advantage (Huxham \& Vangen, 2005; Kanter, 1994; Lampel et al., 2000).

Following this introduction, the theoretical background of the article is described. Then, the case is introduced, and the methods are outlined, explaining the data collection and analysis approach. This is followed by the presentation of the findings of the empirical analysis. The article ends with a discussion of the results and conclusions, including implications for practice and suggestions for further research.

\section{Theoretical Background}

Turbulent operational environments challenge the performance and sustainability of organisations, leading to organisational tensions that require managerial attention (DeFillippi et al., 2007; Ghezzi, 2013; Ramus et al., 2017). The rapidly evolving technology and production environment of the media industry require developing knowledge, skills, and resources that are no longer viable to maintain in-house even for large and established media companies. New collaborative arrangements, for example, in the form of partnerships, value networks, or media clusters, are needed to cope with this new reality and achieve the necessary innovative development (Lowe \& Stavitsky, 2016; Virta \& Lowe, 2017). The changes sweeping the media industry call for modification, if not reformation, of organisational forms, performance, and management practices of media work (Küng, 2017a; Picard \& Lowe, 2016). The ample shifts within the context of media organisations implicate the need for reconceptualization towards more fluid and boundary-crossing collaborative approaches (Hitters \& Richards, 2002; Virta \& Lowe, 2017), which is evident in the growth of the media cluster phenomenon internationally (Achtenhagen \& Picard, 2014; Karlsson \& Picard, 2011; Komorowski, 2017).

Definitions of collaboration vary, and the concept has been used interchangeably with concepts such as consortium, alliance, or partnership, where the role of formal or contractual relationships is often essential (Bryson et al., 2015). The concept of collaboration refers to working together (Kaltoft et al., 2006) in a cooperative interorganisational relationship (Phillips et al., 2000). Overall, definitions of cross-sector collaboration "stress a continuum of progressively more intense interorganizational relationships" (Bryson et al., 2015, p. 648). This article follows Bryson et al.'s (2006, p. 44) more focused definition 
of cross-sector collaboration as "the linking or sharing of information, resources, activities, and capabilities by organizations in two or more sectors to achieve jointly an outcome that could not be achieved by organizations in one sector separately."

Media work and production are characteristically collaborative (Eikhof, 2014; Townley et al., 2009). In creative industries generally, cross-sector collaboration is increasingly common, useful, and necessary in the current uncertain environments (cf. Bryson et al., 2015). It is also typically encouraged by policymakers and other public actors (Kettl, 2015), which has put cross-sector collaboration strongly on their agenda. Nevertheless, such collaboration features complexities and tensions due to its dynamic, multilevel systemic nature (Bryson et al., 2015; Huxham \& Vangen, 2005). Thus, despite the expected usefulness of collaboration, partners often find collaborating troublesome and frustrating in practice (Bryson et al., 2015).

The capacity for innovation is crucial for media organisations facing current changes in their operational environments and business models. Media clusters can offer potential for creating collaborative advantage in content innovation and digital production. This is because hybrid organisations may demonstrate high-level innovativeness (Battilana et al., 2012; Mongelli et al., 2017), or at least they are argued to offer important capacity for innovation (Jay, 2013). However, hybrid organisations face instability and sustainability challenges due to characteristic tensions that arise from the need to combine fundamentally different organisational elements and logics (Battilana et al., 2015). These tensions may hamper the performance or even threaten the existence of hybrid organisations in practice (Jay, 2013; Mongelli et al., 2017).

Hybrid organisations feature dualities (cf. Sutherland \& Smith, 2011), such as simultaneous commercial and non-commercial objectives (Ashforth \& Reingen, 2014; Battilana et al., 2012). Creative organisations, including media, are also fundamentally characterised by dualities (Achtenhagen \& Raviola, 2009; Küng, 2017b), such as continuous tensions between creative freedom and business orientation (e.g., Caves, 2000; DeFillippi et al., 2007; Deuze, 2011; Lampel et al., 2000). Furthermore, creative media organisations in the current context are required to simultaneously "innovate and optimize, which is expressed in the need for diversity and harmonization, for autonomy and centralisation" (Küng, 2017b, p. 207).

The case of Mediapolis, a media cluster and cooperative in Finland, combines publicly and privately funded organisations. Tensions reflect dynamic interrelationships and struggles between the seemingly opposing but interdependent elements of corresponding dualities (cf. Achtenhagen \& Melin, 2003; Farjoun, 2010; Sutherland \& Smith, 2011) that are inherent to hybrid organisation development. The analysis focuses on tensions in implementing collaboration in practice, because successful management of tensions increases the value-creation potential of cross-sector collabora- tions (Koschmann et al., 2012). The research questions are:

RQ1: What organisational tensions and dualities arise in media work in the cross-sector collaboration of media clusters?

RQ2: How to manage the collaborative tensions that emerge?

The findings contribute to extant research by elaborating on the central role of co-existing organisational tensions as a managerial challenge in dealing with the complexities of collaboration in the media industry. Despite shared goals and collaborative strategies, collaboration is complicated by various tensions due to partners' diverging strategies, organisational logics, interests, and goals. Accordingly, developing the work in media clusters is constrained by existing orientations, operational models, and interests of the participating organisations. In the following, the empirical context of the study is discussed.

\section{Methods}

\subsection{Description of the Case}

The empirical case context (Miles et al., 2014; Stake, 1995) of this article is a media cluster called Mediapolis in Finland. The case was chosen because it provides a unique opportunity to analyse the managerial issues and tensions in creating and developing cross-sector collaboration in media work (cf. Smith \& Lewis, 2011). Mediapolis was launched as "a campus" in autumn 2014, when extensive renovations of the premises were finalised, and the first private companies moved in as tenants of Technopolis (real estate operator on site previously owned by the Finnish Broadcasting Company). Mediapolis has been described on its website as "a centre of storytelling and digital industries" and as "a growing and developing centre and network of media companies and organisations" (Mediapolis, 2021, para. 1). In the following, the Mediapolis case is described in terms of its aims, partners, initial development, and operations.

The case organisation features core characteristic of a hybrid organisation in combining entities with differing organisational logics and identities (cf. Jay, 2013). The Finnish Public Service Broadcasting Company, Yleisradio (abbreviated Yle), and two educational institutions-Tampere University of Applied Sciences (TAMK) and Tampere Vocational College (Tredu)represent the public, non-commercial side of the collaboration. TAMK and Tredu have their media-related schools on the Mediapolis campus. In addition, the Business Tampere (part of the Tampere Region Economic Development Agency) has been strongly involved in the Mediapolis development. The private organisations in this study comprised the original Mediapolis real estate 
operator Technopolis (2012-2019) and various commercial media production companies. These included, e.g., AitoMedia production company (producing mainly TV series), which employs approximately 25 media professionals as well as around 5 to 7 (depending on the time of observation) small 1-to 2-person media production companies (focusing on TV or multimedia production, including VR, or both). In addition to media-related organisations, private companies in the fields of management consulting or information technology, catering and health-related services are also located in Mediapolis premises. This case study focuses on the media-related participants of Mediapolis and Technopolis as the real estate operator.

Collaborative initiatives between public and private partners are typically emphasised and stipulated in public funding (cf. Stone et al., 2013). Also, in the case of Mediapolis, the initial development in 2011-2014 was supported by public resources and funds. These include support coordinated by the Tampere City and the Pirkanmaa Region, especially in the initiation stage, in both the Creative Tampere initiative, which aimed to enhance creative industries in the region in general and especially in two rounds of the European Union (EU) project funding. Public funding resulted in the formation of a collaborative company, i.e., Mediapolis Cooperative, in January 2016. It is a legal entity (cf. Chaddad, 2012; Ménard, 2007) comprising the main Mediapolis partners (Yle, TAMK, Technopolis, and AitoMedia at the time).

The Mediapolis Cooperative was founded for managing the Mediapolis shared operations. The aim was set to solve the initial collaborative management problems that were characteristic to early stages of the cluster development. The Mediapolis Cooperative was also expected to sustain itself as a business after an inception period by creating revenue from organising Mediapolis events and happenings. Initial ideas for income generation included selling production piloting services utilising the Yle and Tredu studio facilities on the premises or developing and leading projects financed by public sources such as the EU. However, the management and business models of Mediapolis remained unclear and unspecified. As a result, the partners have been critically analysing the role and identity of the Mediapolis Cooperative and its future.

\subsection{Data Collection}

The data collection for this study comprised four rounds of semi-structured interviews: March-April 2013, November 2015, March 2016, and February 2017. The semi-structured interviews formed the empirical data for the case analysis. The interviews cover the Mediapolis development over time and include the central actors involved in the process. The key informants interviewed were the Mediapolis Cooperative Board members and other key actors in the immediate surroundings of Mediapolis development, such as
Tampere city representatives, external consultants, or entrepreneurs on site. The interviewees represented managerial positions (administrative and program production) of both public and private organisations, individual program producers and production company entrepreneurs, as well as product and program developers on site. Also, internal and external consultants involved in the cluster development and respective product development processes were interviewed. The purposive sample of interview participants (Patton, 2015) included 15 individuals from 12 organisations, and they participated in 23 interviews. Each respondent was interviewed 1-3 times over the research period.

The first round of interviews took place during initial Mediapolis planning, approximately 1.5 years before the launch of the Mediapolis campus in autumn 2014. The most recent interview round was carried out one year after the formation and official establishment of the Mediapolis Cooperative as a legal entity. The length of individual interviews varied between 20 minutes and 1 hour and 51 minutes, and the interviews summed to 24 hours of recorded material. All interviews were conducted by the first author in Finnish. The interviews were digitally recorded, and transcribed. The respondents were promised strict anonymity with regard to their identities and connections to specific organisations.

In addition to the interviews, Mediapolis partners provided the author with extensive access to different forms of empirical material on the case concerning the whole period of Mediapolis development. The research project included selected Mediapolis documentation (e.g., strategy documents and final reports of EU-funded development projects). Furthermore, informal discussions with the chair of the Mediapolis Cooperative Board were conducted regularly (10 times between November 2014 and October 2017, duration of 1-3 hours). These discussions constituted an important gateway to the necessary background information and functioned as "member checking" for trustworthiness of the research results (Creswell, 2014).

\subsection{Analysis Approach}

The analysis approach was inspired by the iterative and abductive process, which Jay (2013) used to analyse paradoxes in hybrid organisations. As is typical for qualitative research, the analysis process started by making initial interpretations of the empirical material (Miles et al., 2014). The first author made notes after each interview to capture the nuances and details, thereby forming a preliminary understanding of the empirical data. The interview transcripts were uploaded to Atlas.ti analysis software (version 8), which was utilised in the coding of the material.

The analysis process was divided into three phases. First, the empirical material was initially explored and reviewed. The transcripts were read in detail several times to create an overall understanding of the data. 
In the second phase, versus coding (Saldaña, 2009) was utilized as observable tensions and conflicts in relation to Mediapolis collaboration emerged as central features in the data. Versus coding identifies phenomena, processes, or organisations in binary terms and in conflict with each other. This made versus coding appropriate for the study of dualities in this article. Accordingly, phrases and excerpts capturing actual and conceptual conflicts were identified and coded (e.g., "public vs. private," "individual vs. collaboration," "agility vs. rigidity"). As suggested by Saldaña (2009), the more detailed coding utilised a grounded approach (Glaser \& Strauss, 1967/2009), resulting in 98 individual codes (e.g., "bottleneck," "collaborative advantage," or "conflicting aims").

In the third phase, the analysis process became an iterative process of reflection back and forth between extant literature and empirical material, enabling more composite and abstract themes to be identified as key dualities and tensions of collaboration in Mediapolis development. These included differing organisational orientations, incongruences between strategy and action, and conflicting interests and contradictions concerning collaboration. In addition, following Jay (2013), the timing of events in the Mediapolis development process was mapped against the composite themes to construct an understanding of the Mediapolis development process.

In the analysis, the respondents were randomly numbered (one number between 1 and 15 per respondent). This numbering is used when the respondent quotes are provided for illustrative purposes. The illustrative quotes from the empirical material have been translated from Finnish. The findings based on the empirical analysis are discussed next.

\section{Findings}

The empirical case in this article features a media cluster aiming at content innovation between publicly and privately funded organisations. The analysis focuses on organisational tensions and managerial challenges of making Mediapolis work as a collaborative arrangement in practice. The tensions emerge as dynamic interrelationships between constituent elements of dualities. For clarity, the core dualities and respective tensions identified in the analysis are discussed separately despite their overlapping features. Tensions regarding each duality are summarized first, and excerpts from the empirical material used as illustrations.

\subsection{Duality 1: Organisational Inertia vs. Operational Agility}

The first duality emerges from differing organisational logics and dynamics, which Mediapolis aims at combining. Tensions between public and private orientations reflect the fundamentally different aims, cultures, and operational practices of the collaborating organisations. The private companies' aspirations suggest a focus on profit and growth, whereas public organisations seem to value stability and long-term development, which builds on established practices. Accordingly, the public organisations' organisational inertia, bureaucratic decision-making, and strong dependence on public policies and regulation collide with the flexibility, willingness to take risks, and dynamic operational realities of the private companies. In Mediapolis, the overreliance on the public organisations' role as anchors of the cluster development seemed to further amplify the tensions in this regard.

As Mediapolis development moved towards operationalisation of the collaboration, tensions especially between public service and private commercial orientations increased. A respondent illustrated the fundamental differences between the operational aims and realities between public and private organisations, which hampered Mediapolis development:

It has been surprisingly slow.... guess it is partly because we have these public actors here; the biggest organisations are public companies, so the ability and willingness to take risks is rather small. Or it is different. There are very few big or even medium-sized [private] companies here that are financially sound and aiming for growth. (Respondent 11)

Yle's central roles as the initiator of Mediapolis, as the buyer organisation for creative production companies' content offerings, and later the possessor of the Mediapolis Cooperative chair position were crucial for Mediapolis' initial development. The collaborating participants acknowledged this, for example, in the following comment:

It [Mediapolis development] started with Yle's willingness to open up and create partnerships. That's where it started, yes. (Respondent 1 )

At the same time, Yle's central role was also a source of tension and development challenges, and Yle's organisational inertia deriving from its public service logic and identity was one of the main obstacles in Mediapolis' practical operations:

How could we remove the Yle stopper....[Yle] Board should hear all this; they should hear that we are well on the way, but the obstacle is this, hey, really, they [Yle] have been doing this same thing since 2012. The progress has been truly slow; it's horrible to say....In these first stages, Yle must be the driver here....Yle [needs to come] out of its bunker. (Respondent 1)

The tensions concerning public-private orientation were especially evident in the different decision-making processes and time frames between the public and private organisations at Mediapolis. A respondent stated: 
One thing that has been told to the Yle management is that we need to be able to make decisions more promptly. (Respondent 15)

Yle was also considered an unpredictable collaboration member, whose actions could abruptly and fundamentally change the dynamics of Mediapolis. This was amplified by the fact that Yle as the Public Service Broadcaster is regulated by specific legislation and by the Finnish Parliament through an Administrative Council. The situation was further complicated by the surprising nomination of an external parliamentary committee to evaluate Yle's mandate and tasks at the time of Mediapolis development. Yle and the other Mediapolis partners had to wait for the results of the committee's work before making further plans or decisions. These unexpected effects of public policy decisions concerned not only Yle but also the other public partners of Mediapolis, especially TAMK, a central reason being the unpredictable changes and cuts in state financing for its operations. A respondent described the situation as follows:

The two biggest things that have had an effect are the challenges created by the [parliamentary] working group and the collapsed financing of the applied science universities. (Respondent 11)

Tensions in relation to the varying orientations between the educational institutions (TAMK and Tredu) and the private media companies in Mediapolis were due to colliding approaches towards everyday realities of media production and teaching it. The industry requirements emphasized future-orientation, agility and speed in action, whereas education built on long-term, established plans and curricula. As respondents stated:

Because there is the problem, we know that the teachers who get stuck in teaching there, they are [mentally] rather far away [from the everyday production realities]....There are several problems. It concerns equipment and also how the teaching happens. When we always came back to this and had meetings, I ended up somehow saying that this is waste of time, this will not lead anywhere, they have isolated themselves in there. (Respondent 13)

It has been a bit painful at times because the commercial companies want their fair share and ask, what is the benefit for them, so that it is not only acting as tutors for the interns. (Respondent 14)

\subsection{Duality 2: Visionary Planning vs. Practical Implementation}

Tensions residing in the duality between ideal planning and practical actions hinges on the imbalance between agreement on the strategic level and concrete action on the practical level. A shared vision is a significant foundation for cross-sector collaboration, but it does not compensate for lack of progress in concrete terms. Planning collaborative governance "in theory," i.e., separate from and ahead of actual experimentation and practices in media work, seemed to hinder Mediapolis progress and add to the frustration of not achieving the targets established. Additionally, strong reliance on public funding and the respective requirements of planning before action seemed to intensify the disparity between long-term visionary planning for explorative development and short-term exploitative action for tangible end results.

In the beginning of Mediapolis development, the partners shared a vision and agreement on the general aims of the collaboration, as illustrated by quotes from the early days:

The big picture in Mediapolis is that it is a great shared dream. (Respondent 11)

In real terms, we have had a vision and goal all the time. Mediapolis is a centre for storytelling and digital industries. (Respondent 6)

The shared vision was crucial for securing the commitment of the participating organisations and for acquiring public funding for the early development of Mediapolis. However, operationalising the strategiclevel intent required shared operational processes and practices, which were lacking. This led to confusion and hindered Mediapolis development in concrete terms, as illustrated by these quotes:

On the level of strategic talks, we all think and share the vision that this is how it should work. But the truly hard basic work where the issues really become clear is still not done. (Respondent 13)

The shared space has been a bit too big and unclear, and this has hindered the advance of the small concrete things. And then many have wondered what is done here and why nothing happens....Somehow the 'shared' has not become concrete enough concerning who wants what. It is usually the small things that lead to a collapse, not the big ones. It is quite possible to agree on the big issues, but somehow the smoothness of everyday actions is what determines the outcome. (Respondent 5)

Tensions between strategic-level visionary planning and corresponding applied action frustrated the private companies in particular, who were expecting practical beneficial results sooner. One of them described the situation as follows:

In a way, the lead time for vision implementation has been way too long, and then it is easy to forget about the vision. What I came here to establish was 
an international-level media hub, and this ambition tends to be forgotten all the time. (Respondent 10)

In the operationalising process of Mediapolis collaboration, significant effort was made to create plans, functional models, and management principles for Mediapolis operations and practices in advance, i.e., before actual concrete action. This was strengthened by public funding allocated for the planning projects. The project work involved several external consultants who concentrated on mapping out the Mediapolis operational model of collaboration, management systems, and the Cooperative's potential business opportunities. Despite the shared approach and objectives, the overemphasis on planning governance before practical actions became one of the central causes of frustration in relation to the lack of progress and the pursuit of outcomes for shared value. The respondents described the results of the consultant-based governance planning projects as follows:

We stated in the concluding event of the project that all the partners were a bit disappointed. It took two or three years, and what was left, lousy web pages. (Respondent 13)

Well, in fact I realised [something] when the productization of the piloting process and the whole operational model [of Mediapolis] had been commissioned two times externally.... [but] it has not led to anything. (Respondent 15)

An illustrative example of tensions between planning and actions was evident in the development of the piloting process as a Mediapolis Cooperative potential product. The shared strategic aim for Mediapolis was to become a platform for new content development, piloting, and innovation, thus serving the vitality of the Finnish audiovisual industry. One of the original core aims of Mediapolis development was to open Yle's resources for wider use, because Yle had unique resources in its newly modernised digital studios and other production facilities which were not in full use by the company itself. Mediapolis participants were looking forward to practical collaboration in this regard. They considered this as key for Mediapolis success, but they expressed some doubt at the same time:

The most crucial point is that Yle will open up not only in ceremonial and festive talks but also in concrete, real terms. (Respondent 11)

Sometimes I have sensed some irritation from the smaller participants because many of them thought when moving to the premises that the studios will immediately open to everyone. But that was the goal; the process of the public organisation was not as smooth as we thought it would be. (Respondent 2)
Collaboration was difficult to implement in practice. One of the core challenges was the creation of viable pricing principles and practice for studio use in piloting processes. Yle had invested heavily in production technology, which created severe pressure in setting prices too high for partners to have a viable chance to use the resource. Additionally, private production companies hoped to be able to use the studios flexibly with short advance notice. This was compromised by the requirement of Yle personnel to operate the equipment, which added to the costs as well as prolonged the planning periods beyond the hopes and expectations of the private partners, who tried to react swiftly to reach potential production deals. In the end, the only way forward was to simulate the actual process among the partners and thus identify the operational bottlenecks to be solved. A respondent explained as follows:

It [finding a solution to the piloting process and pricing] is possible when our cultures are grounded by time and through a sufficient number of cases.....For a long time, everyone calculated their own prices in their own ways. The diagnosis was that these prices don't work or sell... there has been work to clarify and a lot of sitting, and all kinds of things are on paper, but this stage does not take us anywhere, and we have to do this workshop type of thing where we have a representative from a production company involved to go through it all in practice. (Respondent 13)

\subsection{Duality 3: Self-Interest of Individual Organisations vs. Collective Interest in Altruistic Collaboration}

Tensions between the duality elements of self-interest of individual organisations and the collective interest in collaboration illuminates the complexity of combining the collective strategy of the media cluster and the strategies and operational aims of the individual partner organisations. A structure or governance instrument to support cross-sector collaboration may be essential, but its creation seems to require a mandate, ability, and willingness to make decisions collaboratively. Mediapolis partners indicated varying and altering understandings of what collaboration in media work actually implies and requires, which potentially exacerbated the tensions between individual and collective organisational interests.

Tensions between self-interests of individual organisations and the collective interest for collaboration were severe and persistent issues that complicated Mediapolis development. The overall aim of the creation of shared value was described as unclear or non-existent as a result of the collaborative relationships in the Cooperative becoming formalised:

We had several options when we founded the Cooperative. We could have continued as a project but ended up with the Cooperative. We have now 
operated for a year, and I don't think the added value can really be reclaimed in one year. No, I cannot say what added value it has produced. (Respondent 11)

The Mediapolis Cooperative was only partly able to moderate the tensions between interests, despite the intended central role in achieving this. The Mediapolis Cooperative was established with the aim of acting as a structure for the creation of collaborative advantage. However, the hybrid organisation lacked decisionmaking power of its own to succeed in this because it was completely dependent on the individual organisations' decisions and processes. This severely hampered improvement regarding the collaborative interest, as illustrated below:

Or that we could in real terms here together make decisions on some issues, like, OK, now we start this kind of a piloting process and there and these partners are involved. We always have to get confirmation and backing from everyone's own organisation. And even then, they need to process it internally. (Respondent 15)

The partnering organisations of Mediapolis were in principle committed to cross-sector collaboration, but the manifestations in individual organisations varied. A special feature of the tensions between varying interests concerned the use of working time for Mediapolis issues. This was especially evident in the large organisations involved in the Mediapolis Cooperative, despite the fact that they had ample resources and central roles in the collaboration. The respective organisations were in principle highly committed to Mediapolis development on the strategic level, for example, as official members of the Cooperative, but they were strongly bound to their own corporate aims, strategies, and principles in practice. The current operations required by the participants' organisations seemed to overrule the coexploration that Mediapolis was supposed to achieve for the collective interests. As a concrete example, the Mediapolis development process required much effort and focus from the nominated persons, and when this happened, the respective individuals were reminded by their organisations that too much work time devoted to the Mediapolis project was not advisable. The following quote illustrates this situation:

Well, yes, we do without asking, but it's also a bit like saying that no, I don't use much time there for this, you know, everyone has their hobbies....You can also have work as a hobby [when it is not approved as real work by your boss]. (Respondent 1 )

Collaboration for the collective interest as such was considered an asset in receiving public funding or as a tool to fulfil the social responsibilities of the large public organisations in Mediapolis. However, the small private production companies set their priorities clearly to focus on their individual business and benefit despite the shared ideal of collaboration. Due to limited resources, the small private companies chose to focus on self-interested exploitation and everyday business. Respondents explained:

I won't do for a second anything that does not seem to lead to concrete business transactions [for our company]. I don't use time for anything else. (Respondent 10)

It is very difficult to get partners that would really share the business risk. Now there is no time to think about that kind of issue. (Respondent 4)

All in all, the individual strategic interests of each organisation involved in the Mediapolis Cooperative in particular, and in Mediapolis collaboration in general, remained different, which obstructed shared value creation. Despite the shared aim of creating a "media hub" for innovative production, organisations preferred their own agendas: Yle was initially focused on relinquishing real estate ownership as well as implementing its openness and partnership strategy, Technopolis was looking for opportunities to widen its real estate business portfolio in the Tampere area, and Tampere city was concerned with securing a continuous Yle presence and strengthening the role of creative industries and businesses in Tampere.

\section{Conclusions}

In earlier research, collaboration is considered valuable and necessary support for knowledge-intensive organisations for the required flexible and dynamic responses to the rapidly changing operational environments (e.g., Biancani et al., 2014; Ramus et al., 2017). Building on empirical case analysis (cf. Eisenhardt, 1989), this article enriches scholarly discussion on the complexities of collaboration in developing media clusters and in hybrid organisations in two main ways. First, this work contributes to extant theory (Battilana et al., 2015; Jay, 2013; Ramus et al., 2017) by elaborating on the prominent role of organisational tensions as a managerial challenge requiring recognition and action in developing hybrid organisations. Second, the article provides much-needed empirical support for the theoretical underpinnings of creating hybrid organisations by illustrating the inherent tensions that emerge as interrelations between dual organisational elements or forces.

In cross-sector collaborations, the resources provided by the participants can be considered complementary in supporting the aims of the collaboration. However, the media cluster case analysed in this article suggests that the picture is more complex. Despite shared overall goals and strategies towards collaborative opportunities, collaboration is challenged by various 
tensions due to partners' diverging strategies, organisational logics and interests, and collaboration goals, thereby making development constrained by the existing orientations, operational models, and interests of the participating organisations. Addressing these tensions requires specific managerial attention and boundarycrossing practices both internal to and across collaborating organisations.

The case analysis exposed dualities and respective organisational tensions in relation to (a) differing organisational orientations and business logics, (b) incongruence between strategic intent and practical outcomes, and (c) conflicting interests between organisations. In the findings, the respective dualities were labelled as (1) organisational inertia vs. operational agility, (2) visionary planning vs. practical implementation, and (3) selfinterest of individual organisations vs. collective interest in altruistic collaboration. Tensions relating to each duality were explained. Although the results of the analysis illustrate the dualities and corresponding tensions as distinct, they are interrelated in practice. For example, the differing organisational orientations are reflected in strategic intents, which connect to differing expectations of speed and clarity in reaching practical outcomes and placing individual organisations' immediate gain over collective benefits. As a result, tensions coexist and require managerial attention as an interrelated and dynamic package.

Trade-offs between public (or non-commercial) and private (or commercial) organisations are crucial in crosssector hybrid organisations (Battilana \& Lee, 2014), as well as in formalising inter-organisational cooperation more generally (Vlaar et al., 2007). The logic of public sector organisations in focusing on long-term viability and development collides with the short-term business imperatives and profit orientations of private partners. This article concludes that identifying and successfully managing the coexisting tensions of collaboration is key in finding the necessary trade-offs for establishing crosssector collaboration in the media industry, particularly in media clusters.

In the Mediapolis Cooperative specifically and in collaboration more broadly, the participants have to rely on the willingness of other partners to share knowledge and other necessary resources for the collaboration to succeed (cf. Phillips et al., 2000). The shared engagement is difficult to achieve because the individual strategic focus of the collaboration participants may easily overrule the shared vision and development despite the agreements or even legal contracts. In this regard and in accordance with earlier studies (e.g., Hitters \& Richards, 2002), the individual agenda of the participating organisations in the Mediapolis Cooperative was their main concern, not the Mediapolis development. The idea of Mediapolis as a fully integrated hybrid organisation (see Battilana et al., 2012) was not transformed from executive-level presentations and visionary collaboration plans to everyday media work in real terms. The shift of focus from indi- vidual organisations' interest to the collaborative interest necessitates understanding that these shifts require reconceptualization of current organisational principles and practices of the participating organisations in order to avoid centripetal effects of self-interest in relation to collaboration.

Collaborative practices are necessary for creating collaborative advantage. Changes are required not only on the collaboration level but also within each partner itself (cf. Bryson et al., 2015; Kanter, 1994). The Mediapolis case analysis surfaced considerable internal tensions in the core anchor organisations of the cluster, and these led to respective tensions in the overall cooperation. This finding suggests that successful collaboration requires a shift from management approaches emphasising vertical angles including structure and order in the "home" organisation to more horizontal and lateral perspectives, emphasising the importance of collaborative processes and mutually beneficial relationships. Collaboration does not feature an equilibrium; instead, it is in constant flux and requires balancing the strategic objectives of individual organisations with producing shared value for collaborative advantage.

Despite the overall strategic-level agreement on collaboration, it is crucial to identify the potentially different goals that the participants aim to achieve. This understanding is necessary to anticipate the implementationstage managerial problems and practical challenges of establishing the collaboration, especially for defining when the collaboration can be considered successful and by which criteria. Unlike the suggestion from earlier research by Ramus et al. (2017), the case study in this article does not support the assumption that clearly defined formal processes would necessarily pave the way for smooth collaboration; rather, it emphasises the key importance of flexible and dynamic managerial approaches. Thus, the article has practical implications for managers in creative industries aiming to create collaborative organisational arrangements for shared value creation and content innovation in media work.

This study has limitations worth noting. It presents a single case study, which suggests limited generalisability of the results. Additionally, potential researcher bias is evident because the interviews were conducted by the sole researcher. However, multiple sources of empirical data, long-term access to the case, researcher triangulation in the analysis, and member checking with respondents support the credibility of the results (Creswell, 2014).

Finally, future research should focus on dimensions across different analytical levels of collaboration and hybrid organisations in the media industry. Deeper understanding would benefit from considerations, e.g., on the micro (individual), meso (interaction between actors), and macro (external factors) levels. The complexity of the phenomenon calls also for dynamic and systemic approaches and comparative qualitative case studies, e.g., between media and other types of creative clusters. 


\section{Acknowledgments}

The authors wish to thank Professor Charmine Härtel for her valuable comments and support.

\section{Conflict of Interests}

The authors declare no conflict of interests.

\section{References}

Achtenhagen, L., \& Melin, L. (2003). Managing the homogeneity-heterogeneity duality. In A. M. Pettigrew, R. Whittington, L. Melin, C. Sánchez-Runde, F. van den Bosch, W. Ruigrok, \& T. Numagami (Eds.), Innovative forms of organizing: International perspectives (pp. 301-327). SAGE.

Achtenhagen, L., \& Picard, R. G. (2014). Challenges and success factors in media cluster development: A review of contemporary knowledge. In C. Karlsson, B. Johansson, \& R. R. Stough (Eds.), Agglomeration, clusters, and entrepreneurship: Studies in regional economic development (pp. 221-251). Edward Elgar.

Achtenhagen, L., \& Raviola, E. (2009). Balancing tensions during convergence: Duality management in a newspaper company. The International Journal on Media Management, 11(1), 32-41.

Ashforth, B. E., \& Reingen, P. H. (2014). Functions of dysfunction: Managing the dynamics of an organizational duality in a natural food cooperative. Administrative Science Quarterly, 59(3), 474-516.

Battilana, J., \& Lee, M. (2014). Advancing research on hybrid organizing: Insights from the study of social enterprises. The Academy of Management Annals, 8(1), 397-441.

Battilana, J., Lee, M., Walker, J., \& Dorsey, C. (2012). In search of the hybrid ideal. Stanford Social Innovation Review, 10(3), 51-55.

Battilana, J., Sengul, M., Pache, A.-C., \& Model, J. (2015). Harnessing productive tensions in hybrid organizations: The case of work integration social enterprises. Academy of Management Journal, 58(6), 1658-1685.

Biancani, S., McFarland, D. A., \& Dahlander, L. (2014). The semiformal organization. Organization Science, 25(5), 1306-1324.

Bryson, J. M., Crosby, B. C., \& Stone, M. M. (2006). The design and implementation of cross-sector collaborations: Propositions from the literature. Public Administration Review, 66, 44-55.

Bryson, J. M., Crosby, B. C., \& Stone, M. M. (2015). Designing and implementing cross-sector collaborations: Needed and challenging. Public Administration Review, 75(5), 647-663.

Caves, R. E. (2000). Creative industries: Contracts between art and commerce. Harvard University Press.

Chaddad, F. (2012). Advancing the theory of the cooperative organization: The cooperative as a true hybrid. Annals of Public and Cooperative Economics, 83(4),
445-461.

Creswell, J. W. (2014). Research design. Qualitative, quantitative, and mixed methods approaches. SAGE.

DeFillippi, R., Grabher, G., \& Jones, C. (2007). Introduction to paradoxes of creativity: Managerial and organizational challenges in the cultural economy. Journal of Organizational Behavior, 28(5), 551-521.

Deuze, M. (2007). Media work. Polity Press.

Deuze, M. (2011). Managing media work. SAGE.

Eikhof, D. R. (2014). Transorganisational work and production in the creative industries. In C. Bilton \& S. Cummings (Eds.), Handbook of management and creativity (pp. 275-297). Edward Elgar.

Eisenhardt, K. M. (1989). Building theories from case study research. Academy of Management Review, 14(4), 532-550.

Ess, C. M. (2014). Introduction to inaugural issue. The Journal of Media Innovations, 1(1), 1-12. https://doi. org/10.5617/jmi.v1i1.821

Farjoun, M. (2010). Beyond dualism: Stability and change as a duality. Academy of Management Review, 35(2), 202-225.

Ghezzi, A. (2013). Revisiting business strategy under discontinuity. Management Decision, 51(7), 1326-1358.

Glaser, B. G., \& Strauss, A. L. (2009). The discovery of grounded theory: Strategies for qualitative research. Aldine Transaction. (Original work published 1967)

Hitters, E., \& Richards, G. (2002). The creation and management of cultural clusters. Creativity and Innovation Management, 11(4), 234-247.

Huxham, C., \& Vangen, S. (2005). Managing to collaborate. The theory and practice of collaborative advantage. Routledge.

Jay, J. (2013). Navigating paradox as a mechanism of change and innovation in hybrid organizations. Academy of Management Journal, 56(1), 137-159.

Kaltoft, R., Boer, H., Chapman, R., Gertsen, F., \& Nielsen, J. S. (2006). Collaborative improvement: Interplay but not a game. Creativity and Innovation Management, 15(4), 348-358.

Kanter, R. M. (1994). Collaborative advantage: The art of alliances. Harvard Business Review, 72(4), 96-108.

Karlsson, C., \& Picard, R. G. (2011). Media clusters: Spatial agglomeration and content capabilities. Edward Elgar.

Kettl, D. F. (2015). The job of government: Interweaving public functions and private hands. Public Administration Review, 75(2), 219-229.

Komorowski, M. (2017). A novel typology of media clusters. European Planning Studies, 25(8), 1334-1356.

Koschmann, M. A., Kuhn, T. R., \& Pfarrer, M. D. (2012). A communicative framework of value in cross-sector partnerships. Academy of Management Review, 37(3), 332-354.

Küng, L. (2017a). Going digital: A roadmap for organisational change. Reuters Institute for the Study of Journalism. 
Küng, L. (2017b). Strategic management in the media. Theory to practice. SAGE.

Lampel, J., Lant, T., \& Shamsie, J. (2000). Balancing act: Learning from organizing practices in cultural industries. Organization Science, 11(3), 263-269.

Lewis, M. W., Andriopoulos, C., \& Smith, W. K. (2014). Paradoxical leadership to enable strategic agility. California Management Review, 56(3), 58-77.

Lowe, G. F., \& Stavitsky, A. G. (2016). Ensuring public service news provision in the era of networked communications. International Communication Gazette, 78(4), 311-329.

Mediapolis. (2021). Mediapolis is a centre of storytelling and digital industries. http://mediapolis.fi/en

Ménard, C. (2007). Cooperatives: Hierarchies or hybrids? In K. Karantinis \& J. Nilsson (Eds.), Vertical markets and cooperative hierarchies (pp. 1-17). Springer.

Miles, M. B., Huberman, A. M., \& Saldaña, J. (2014). Qualitative data analysis: A methods sourcebook. SAGE.

Mongelli, L., Rullani, F., \& Versari, P. (2017). Hybridisation of diverging institutional logics through common-note practices: An analogy with music and the case of social enterprises. Industry and Innovation, 24(5), 492-514.

Patton, M. Q. (2015). Qualitative research \& evaluation methods. SAGE.

Phillips, N., Lawrence, T. B., \& Hardy, C. (2000). Interorganizational collaboration and the dynamics of institutional fields. Journal of Management Studies, 37(1), 23-43.

Picard, R. G., \& Lowe, G. F. (2016). Questioning media management scholarship: Four parables about how to better develop the field. Journal of Media Business Studies, 13(2), 61-72.

Ramus, T., Vaccaro, A., \& Brusoni, S. (2017). Institutional complexity in turbulent times: Formalization, collaboration, and the emergence of blended logics. Academy of Management Journal, 60(4), 1253-1284.

Saldaña, J. (2009). The coding manual for qualitative researchers. SAGE.
Smith, W. K., \& Lewis, M. W. (2011). Toward a theory of paradox: A dynamic equilibrium model of organizing. Academy of Management Review, 36(2), 381-403.

Stake, R. E. (1995). The art of case study research. SAGE.

Stone, M. M., Crosby, B. C., \& Bryson, J. M. (2013). Adaptive governance in collaborations: Design propositions from research and practice. In C. Cornforth \& W. A. Brow (Eds.), Nonprofit governance: Innovative perspectives and approaches (pp. 249-271). Routledge.

Sutherland, F., \& Smith, A. (2011). Duality theory and the management of the change-stability paradox. Journal of Management \& Organization, 17(4), 534-547.

Sydow, J., Müller-Seitz, G., \& Provan, K. G. (2013). Managing uncertainty in alliances and networks: From governance to practice. In T. K. Das (Ed.), Managing knowledge in strategic alliances (pp. 1-43). Information Age Publishing.

Townley, B., Beech, N., \& McKinlay, A. (2009). Managing in the creative industries: Managing the motley crew. Human Relations, 62(7), 939-962.

Villi, M., \& Picard, R. G. (2019). Transformation and innovation of media business models. In M. Deuze \& $\mathrm{M}$. Prenger (Eds.), Making media. Production, practices, and professions (pp. 121-131). Amsterdam University Press.

Virta, S., \& Lowe, G. F. (2017). Integrating media clusters and value networks: Insights for management theory and research from a case study of Mediapolis in Finland. Journal of Management \& Organization, 23(1), 2-21. https://doi.org/10.1017/jmo.2016.56

Vlaar, P. W. L., Van Den Bosch, F. A. J., \& Volberda, H. W. (2007). Towards a dialectic perspective on formalization in interorganizational relationships: How alliance managers capitalize on the duality inherent in contracts, rules, and procedures. Organization Studies, 28(4), 437-466.

Westlund, O. (2012). Guest editorial. Transforming tensions: Legacy media towards participation and collaboration. Information, Communication \& Society, 15(6), 789-795.

\section{About the Authors}
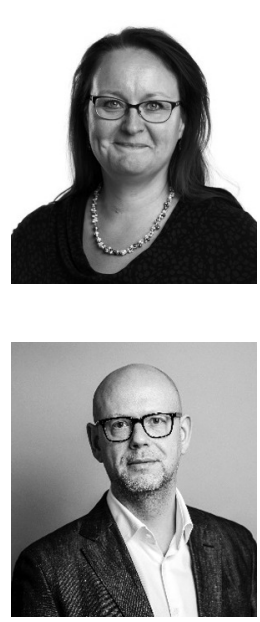

Sari Virta (PhD) is a development manager at the State Treasury of Finland. She is an affiliated researcher at Jönköping International Business School in Sweden and has been a visiting scholar at University of Queensland Business School and Tallinn University. Her research focuses on management of creative organisations and their networks. 